\title{
Review
}

\section{Diabetic neuropathies}

\author{
A.I. Vinik, T.S. Park, K. B.Stansberry, G. L. Pittenger \\ The Strelitz Diabetes Institutes, Eastern Virginia Medical School, Norfolk, Virginia, USA
}

\section{Introduction}

Diabetic neuropathy is a most common and troublesome complication of diabetes mellitus, leading to the greatest morbidity and mortality and resulting in a huge economic burden for diabetes care $[1,2]$. It is the most common form of neuropathy in the developed countries of the world, accounts for more admission to hospital than all the other diabetic complications combined and is responsible for $50-75 \%$ of non-traumatic amputations [2, 3]. Diabetic neuropathy is a set of clinical syndromes that affect distinct regions of the nervous system, singly or combined. It can be silent and go undetected, while exercising its ravages, or be present with clinical symptoms and signs that although non-specific and insidious with slow progression also mimic those seen in many other diseases. It is, therefore, diagnosed by exclusion.

Diabetic neuropathy is a heterogeneous disorder that encompasses a wide range of abnormalities affecting proximal and distal peripheral sensory and motor nerves as well as the autonomic nervous systems. For these reasons, it has been difficult to obtain precise estimates of the true prevalence and reports vary from 10 to $90 \%$ in diabetic patients, depending on the criteria and methods used to define neuropa-

Corresponding author: A. I. Vinik, The Strelitz Diabetes Institutes, Departments of Internal Medicine and Pathology/Neurobiology, Eastern Virginia Medical School, 855 W Brambleton Avenue, Norfolk, VA 23510, USA

Abbreviations: NCV, Nerve conduction velocity; QST, quantitative sensory tests; QAFT, quantitative autonomic function tests; CIDP, chronic inflammatory demyelinating polyneuropathy; MGUS, monoclonal gammapathy of undetermined significance; DSPN, distal symmetric polyneuropathy; ARIs, aldose reductase inhibitors; GLA, gamma linolenic acid; rhNGF, recombinant human nerve growth factor; CGRP, calcitonin gene-related peptide; NMDA, $N$-methyl-D-aspartate; ACE, angiotensin-converting enzyme; $\mathrm{ED}$, erectile dysfunction. thy [1-5]. From patients attending a diabetes clinic $25 \%$ reported symptoms; $50 \%$ were found to have neuropathy after a simple clinical test such as the ankle jerk or vibration perception test; almost $90 \%$ tested positive to sophisticated tests of autonomic function or peripheral sensation [6]. Neurologic complications occur equally in Type I (insulin-dependent) and Type II (non-insulin-dependent) diabetes mellitus and additionally in various forms of acquired diabetes [5]. The major morbidity associated with somatic neuropathy is foot ulceration, the precursor of gangrene and limb loss. Neuropathy increases the risk of amputation 1.7-fold; 12-fold, if there is deformity (itself a consequence of neuropathy), and 36-fold, if there is a history of previous ulceration [7]. There are 65,000 amputations in the United States each year, one every $10 \mathrm{~min}$, and neuropathy is considered to be the major contributor in $87 \%$ of cases. It is also the most life-spoiling of the diabetic complications and has tremendous ramifications for the quality of life of the person with diabetes. Once autonomic neuropathy sets in, life can become quite dismal and the mortality rate approximates $25-50 \%$ within 5-10 years $[8,9]$. In this review we present and discuss the most recent approaches to the diagnosis and treatment of diabetic neuropathy and the prospects on the horizon.

\section{Classification}

Diabetic neuropathy is not a single entity but a number of different syndromes, ranging from subclinical to clinical manifestations depending on the classes of nerve fibres involved. According to the San Antonio Convention [10], the main groups of neurologic disturbance in diabetes mellitus include: (1) subclinical neuropathy, determined by abnormalities in electrodiagnostic and quantitative sensory testing, (2) dif- 
fuse clinical neuropathy with distal symmetric sensorimotor and autonomic syndromes and (3) focal syndromes.

Subclinical neuropathy is diagnosed on the basis of: (i) abnormal electrodiagnostic tests with decreased nerve conduction velocity (NCV) or decreased amplitudes, (ii) abnormal quantitative sensory tests (QST) for vibration, tactile, thermal warming and cooling thresholds and (iii) quantitative autonomic function tests (QAFT) showing diminished heart rate variation with deep breathing, valsalva manoeuvre and postural testing. The results of QAFT also showed diminished sudomotor function and increased pupillary latency.

\section{Natural course}

The natural course of neuropathies separates them into two very distinctive entities, namely those which progress gradually with increasing duration of diabetes and those which remit usually completely. Sensory and autonomic neuropathies generally progress, whereas mononeuropathies, radiculopathies and acute painful neuropathies, although symptoms are severe, are short-lived and tend to recover [11].

Progression of diabetic neuropathy is related to glycaemic control in both Type I and Type II diabetes $[12,13]$. It seems that the most rapid deterioration of nerve function occurs soon after the onset of Type I diabetes and within $2-3$ years there is a slowing of the progress with a shallower slope to the curve of dysfunction. In contrast, in Type II diabetes slowing of NCVs can be one of the earliest neuropathic abnormalities and often is present even at diagnosis [14]. After diagnosis, slowing of NCV generally progresses at a steady rate of approximately $1 \mathrm{~m} \cdot \mathrm{s}^{-1} \cdot$ year $^{-1}$ and the level of impairment is positively correlated with duration of diabetes. Although most studies have documented that symptomatic patients are more likely to have slower NCVs than patients without symptoms, these do not relate to the severity of symptoms. In a long-term follow-up study of Type II diabetic patients [15], electrophysiologic abnormalities in the lower limb increased from $8 \%$ at baseline to $42 \%$ after 10 years and decreased in sensory and motor amplitudes, indicating axonal destruction was more pronounced than the slowing of the NCVs. An increase of about 2 points in an 80point clinical scale can be expected a year. These scales contain information of motor, sensory and autonomic signs and symptoms. Using objective measures of sensory function such as the vibration perception threshold test, the rate of decline in function has been reported as 1-2 vibration units a year. There now seems, however, to be a decline in this rate of evolution. For example, in a recent nerve growth factor study, the vibration perception thresh- old at the beginning of the study in the placebo group was identical to that at the end of 1 year [16, 17]. It seems that host factors pertaining to general health and nerve nutrition are changing. This is particularly important in doing studies on treatment of diabetic neuropathy which have always relied on differences between drug treatment and placebo and have apparently been successful because of the decline in placebo-treated patients [18]. Based upon the earlier estimates of change, clinically meaningful loss of vibration perception and conduction velocity was estimated to take at least 3 years, dictating a future need to carry out studies over a longer time. It is also important to recognise that diabetic neuropathy is a disorder in which the prevailing abnormality is loss of axons and this translates electrophysiologically to a reduction in amplitudes, not conduction velocities and that changes in NCV might not be an appropriate means of monitoring progress or deterioration of nerve function. It has always been advocated that diabetes affects the longest fibres first; hence, the increased predisposition in taller people [19]. Now it seems that small fibre involvement could herald the onset of neuropathy and even diabetes. Small fibre function is not detectable using standard electrophysiology and requires measurement of sensory, neurovascular and autonomic thresholds and cutaneous nerve fibre density $[20,21]$.

There are few data on the longitudinal trends in small fibre dysfunction. Much remains to be learned about the natural course of diabetic autonomic neuropathy. Recently, it has been reported that diabetic autonomic neuropathy progresses during the 2 years subsequent to its discovery [22]. The mortality for diabetic autonomic neuropathy has been estimated to be $44 \%$ within 2.5 years of diagnosing symptomatic autonomic neuropathy [8]. A meta analysis [23] shows that the mortality rate after 5.8 years of diabetes with symptomatic autonomic neuropathy was $29 \%$.

\section{Pathogenesis}

Figure 1 summarises our current view of the pathogenesis of diabetic neuropathy. This figure depicts multiple aetiologies including metabolic, vascular, autoimmune, oxidative stress and neurohormonal growth-factor deficiency. Detailed discussion of the different theories is beyond the scope of this review. The reader is referred to several excellent recent reviews [24-26]. Diabetic neuropathy is, however, a heterogeneous disease with widely varying pathology, suggesting differences in pathogenic mechanisms for the different clinical syndromes. Recognition of the clinical homologue of these pathologic processes is the first step in achieving the appropriate form of intervention. 


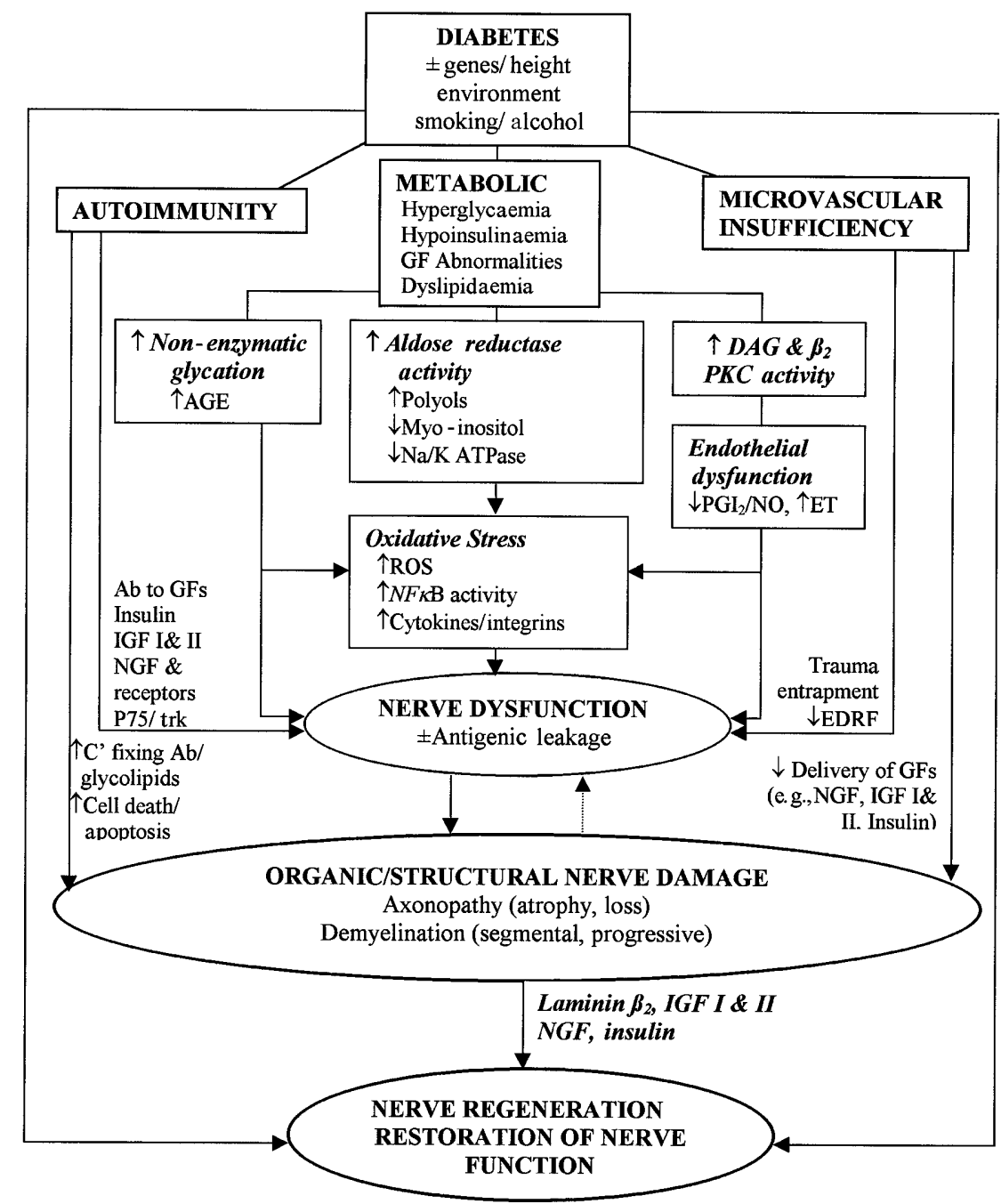

Fig. 1. A theoretical framework for the development of diabetic neuropathy. (Adapted from reference 57). AGE, Advanced glycation end product; DAG, diacylglycerol; EDRF, endothelium-derived relaxing factor; ET, endothelin; NF $x \mathrm{~B}$, nuclear factor $\chi \mathrm{B}$; NGF, nerve growth factor; $\mathrm{NO}$, nitric oxide; ROS, reactive oxygen species; $\mathrm{PKC}$, protein kinase $\mathrm{C} ; \mathrm{PGI}_{2}$, prostacyclin; Trk, NGF receptor

\section{Clinical presentation}

The spectrum of clinical neuropathic syndromes described in patients with diabetes includes dysfunction of almost every segment of the somatic peripheral and autonomic nervous system [27] (Fig.2). Each syndrome can be distinguished by its pathophysiologic, therapeutic and prognostic features.

\section{Focal neuropathies}

\section{Mononeuritis and entrapment syndromes}

Mononeuropathies occur primarily in the older population, their onset is generally rapid, associated with pain and their course is self-limiting, resolving within 6-8 weeks. This is due to vascular obstruction after which adjacent neuronal fascicles take over the function of those infarcted by the clot [28].

Mononeuropathies must be distinguished from entrapment syndromes that start slowly, progress and persist without intervention. Common entrapment sites in diabetic patients involve median, ulnar, radial, femoral, lateral cutaneous nerves of the thigh, peroneal, and medial and lateral plantar nerve. Carpal tunnel syndrome occurs twice as frequently in people with diabetes compared with normal healthy population and its increased prevalence in diabetes can be related to repeated undetected trauma, metabolic changes, or accumulation of fluid or oedema within the confined space of the carpal tunnel [27]. If recognised, the diagnosis can be confirmed by electrophysiologic study and therapy is simple with surgical re- 

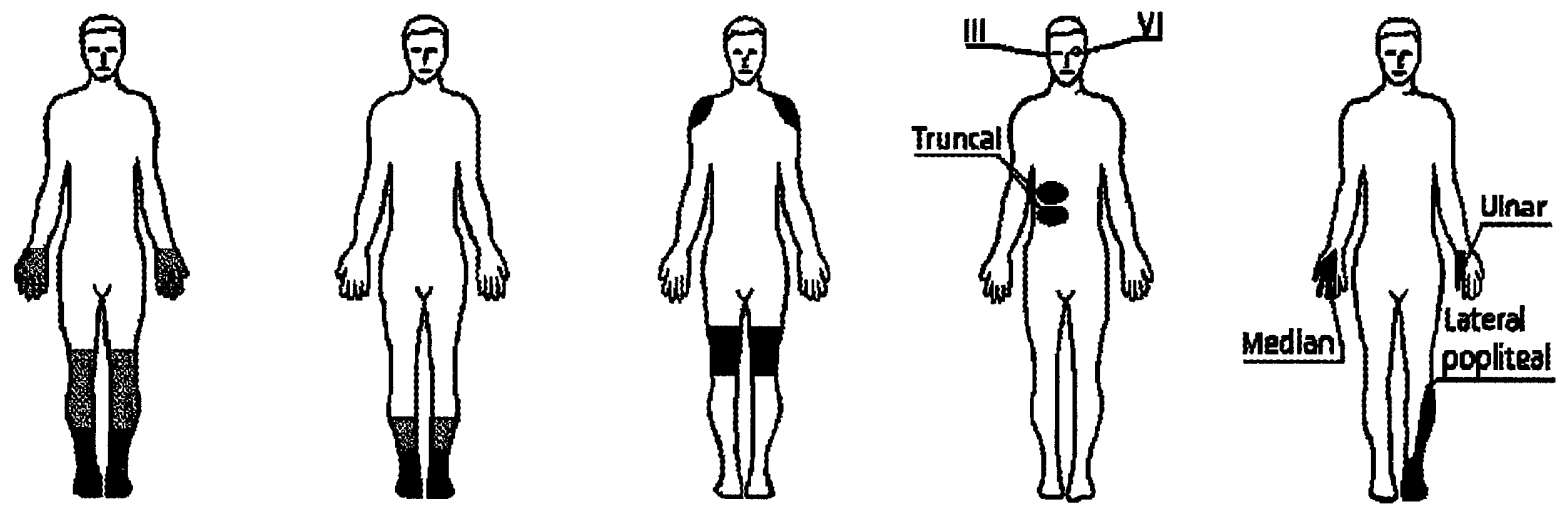

\begin{tabular}{|c|c|c|c|c|}
\hline $\begin{array}{l}\text { Large-fibre } \\
\text { neuropathy }\end{array}$ & $\begin{array}{l}\text { Small - fibre } \\
\text { neuropathy }\end{array}$ & $\begin{array}{l}\text { Proximal motor } \\
\text { neuropathy }\end{array}$ & $\begin{array}{l}\text { Acute mono } \\
\text { neuropathies }\end{array}$ & $\begin{array}{c}\text { Pressure } \\
\text { palsies }\end{array}$ \\
\hline $\begin{array}{l}\text { Sensory loss: } 0 \rightarrow++ \\
\text { (Touch, vibration) } \\
\text { Pain: }+\rightarrow++ \\
\text { Tendon reflex: } \mathrm{N} \rightarrow \downarrow \downarrow \downarrow \\
\text { Motor deficit } 0 \rightarrow+++\end{array}$ & $\begin{array}{l}\text { Sensory loss: } 0 \rightarrow+ \\
\text { (thermal , allodynia) } \\
\text { Pain: }+\rightarrow++ \\
\text { Tendon reflex: } N \rightarrow \downarrow \\
\text { Motor deficit: } 0\end{array}$ & $\begin{array}{l}\text { Sensory loss: } 0 \rightarrow+ \\
\text { Pain: }+\rightarrow++ \\
\text { Tendon reflex: } \downarrow \downarrow \\
\text { Proximal motor deficit: } \\
+\rightarrow++\end{array}$ & $\begin{array}{l}\text { Sensory loss: } 0 \rightarrow+ \\
\text { Pain: }+\rightarrow++ \\
\text { Tendon reflex: } N \\
\text { Motor deficit: } \\
+\rightarrow+++\end{array}$ & $\begin{array}{l}\text { Sensory loss in nerve } \\
\text { distribution: }+\rightarrow++ \\
\text { Pain: }+\rightarrow++ \\
\text { Tendon reflex: } \mathrm{N} \\
\text { Motor deficit: }+\rightarrow+++\end{array}$ \\
\hline
\end{tabular}

Fig. 2. Different clinical presentations of diabetic neuropathy

lease. The mainstays of non-surgical treatment are resting the wrist aided by the placement of a wrist splint in a neutral position for day and night use, and the addition of anti-inflammatory drug medications. Surgical treatment consists of sectioning the volar carpal ligament [29]. The decision to proceed with surgery should be based on several considerations, including severity of symptoms, appearance of motor weakness and failure of non-surgical treatment.

\section{Diffuse neuropathies}

\section{Proximal motor neuropathies (diabetic amyotrophy)}

For many years proximal neuropathy has been considered as a component of diabetic neuropathy. Its pathogenesis was ill understood [30] and its treatment was neglected with the anticipation that the patient would eventually recover, albeit over some 1-2 years, suffering considerable pain, weakness and disability. The condition has a number of synonyms: proximal neuropathy, femoral neuropathy, diabetic amyotrophy and diabetic neuropathic cachexia. Proximal motor neuropathy can be clinically identified based on recognition of these common features: (1) primarily affects the elderly, (2) gradual or abrupt onset, (3) begins with pain in the thighs and hips or buttocks (4) followed by weakness of the proximal muscles of the lower limbs with inability to rise from the sitting position (positive Gower's manoeuvre), (5) begins unilaterally and spreads bilaterally, (6) coexists with distal symmetric polyneuropathy and (7) spontaneous muscle fasciculation, or provoked by percussion. The condition is now recognised as being secondary to a variety of causes unrelated to diabetes but which have a greater frequency in patients with diabetes than the general population. It includes patients with chronic inflammatory demyelinating polyneuropathy (CIDP), monoclonal gammopathy, circulating GM1 antibodies and antibodies to neuronal cells and inflammatory vasculitis [31, 32]. It was formerly thought to resolve spontaneously in 1.5 to 2 years but now, if found to be immune-mediated, can resolve within days with immunotherapy. The condition is readily recognisable clinically with prevailing weakness of the iliopsoas, obturator and adductor muscles, together with relative preservation of the gluteus maximus and minimus and hamstrings [33]. Those people affected have great difficulty rising out of chairs unaided and often use their arms to assist themselves. Heel or toe standing is surprisingly good. In the usual form of diabetic amyotrophy, axonal loss is the predominant process and the condition coexists with distal symmetric polyneuropathy (DSPN) [34]. Electrophysiologic evaluation shows lumbosacral plexopathy [33]. In contrast, if demyelination predominates and the motor deficit affects proximal and distal muscle groups, the diagnosis of CIDP, monoclonal gammopathy of undetermined significance (MGUS) and vasculitis should be considered $[35,36]$. Biopsy of the obturator nerve shows deposition of immunoglobulin, demyelination and inflammatory cell infiltrate of the vasa nervorum [37]. Cerebrospinal fluid (CSF) protein content is high and there is an increase in the lymphocyte count. Treatment options include: intravenous immunoglobulin for CIDP, plasma exchange for MGUS, steroids 

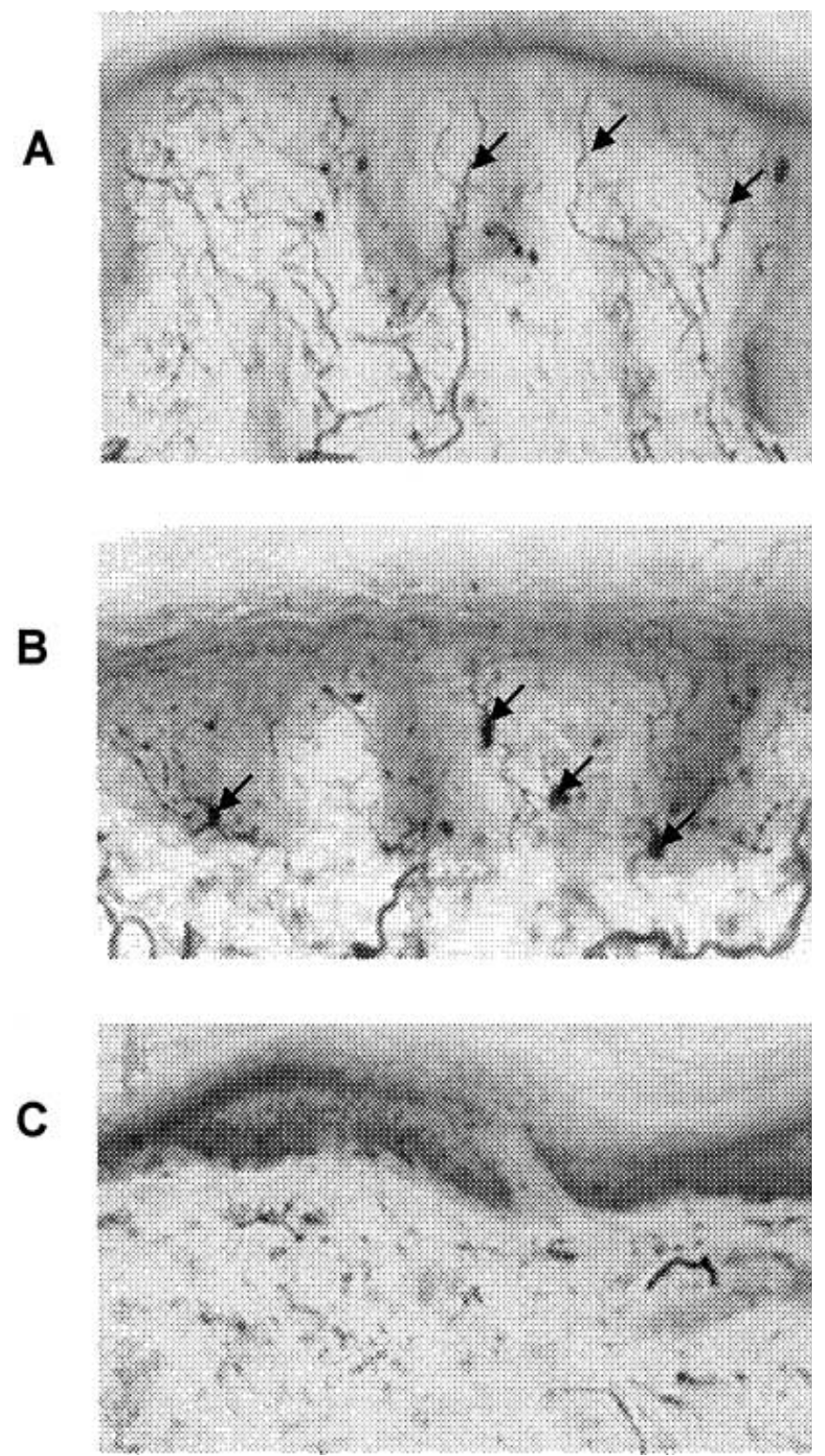

Fig. 3 A-C. Loss of cutaneous nerve fibres that stain positive for the neuronal antigen PGP9.5 in sensory neuropathy. A Normal density of epidermal nerve fibres (arrows) in back. B Slightly reduced density and abnormal nerve fibre swellings (arrows) in proximal thigh. C Complete clearance of nerve fibres in calf

and azathioprine for vasculitis and withdrawal from drugs or other agents that could have caused a vasculitis. It is important to divide proximal syndromes into these two subcategories because the CIDP variant responds strongly to intervention $[35,38]$ whereas amyotrophy runs its own course over months to years. Until more evidence is available, they should be considered as separate syndromes.

\section{Distal symmetric polyneuropathy (DSPN)}

Distal symmetric polyneuropathy (DSPN) is the most common and widely recognised form of diabetic neuropathy. The onset is usually insidious but occasionally is rapid, following stress or initiation of therapy for diabetes. It can be either sensory or motor and involve small fibres, large fibres or both [39].

Small-nerve fibre dysfunction usually occurs early and often is present without objective signs or electrophysiologic evidence of nerve damage [40]. It is manifested by early lower limbs symptoms of pain and hyperalgesia in the lower limbs, followed by a loss of thermal sensitivity and reduced light touch and pinprick sensation [27]. There is now evidence that DSPN can be accompanied by loss of cutaneous nerve fibres that stain positive for the neuronal antigen PGP9.5 [41] (Fig. 3) as well as impaired neurovascular blood flow [42] (Fig. 4). There are, however, a variety of ways in which small fibre neuropathies can present.

\section{Small-fibre neuropathy}

Acute painful neuropathy. Some patients develop a predominantly small-fibre neuropathy, which is manifested by pain and paresthesiae early in the course of diabetes (Table 1). It can be associated with the onset of insulin therapy and has been termed "insulin neuritis" [43]. By definition it has been there for less than 6 months. Symptoms often are exacerbated at night and are manifested in the feet more than the hands. Spontaneous episodes of pain can be severely disabling. The pain varies in intensity and character. In some patients, the pain has been variably de-

Table 1. Clinical manifestations of small-fibre neuropathies

- Symptoms are prominent. Pain is of the C-fibre type. It is burning and superficial and associated with allodynia, i. e. interpretation of all stimuli as painful (e.g. touch)

- Late in the condition there is hypoalgesia

- Defective warm thermal sensation

- Defective autonomic function with decreased sweating, dry skin, impaired vasomotion and blood flow and a cold foot.

- There is remarkable intactness of reflexes, motor strength

- Electrophysiologically silent

- Loss of cutaneous nerve fibres using PGP 9.5 staining

- Diagnosed clinically by reduced sensitivity to $1.0 \mathrm{~g}$ Semmes Weinstein monofilament and pricking sensation using the Waardenberg wheel or similar instrument

- Abnormalities in thresholds for warm thermal perception, neurovascular function, pain, quantitative sudorimetry and quantitative autonomic function tests.

- Risk is foot ulceration and subsequent gangrene (there are 65,000 amputations in the US each year, 1 every $10 \mathrm{~min}, 50 \%$ are preventable!) 


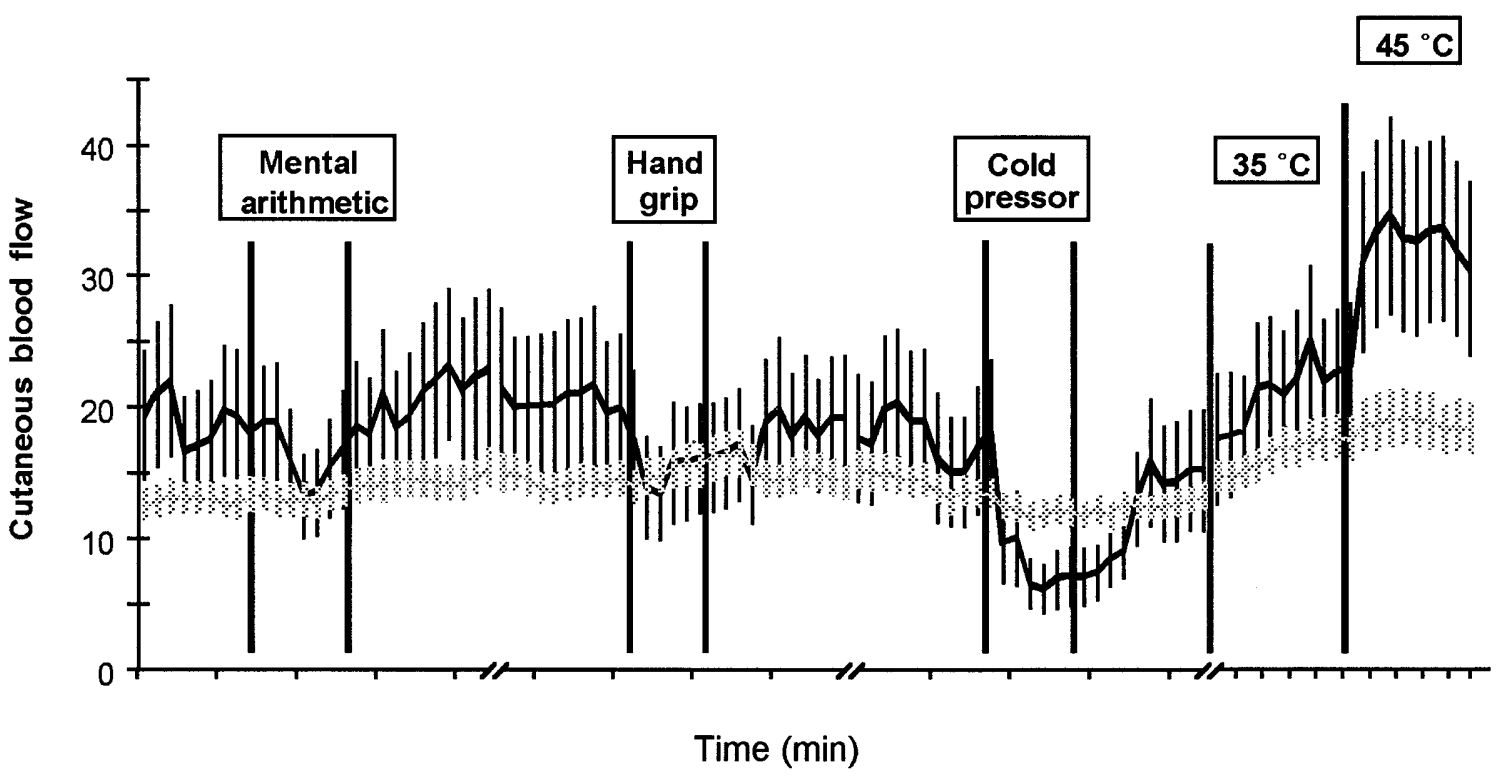

Fig. 4. Impaired neurovascular blood flow in cardiac autonomic neuropathy. (Adapted from reference 42). trol; ........, diabetic patients

scribed as burning, lancinating, stabbing or sharp. Paresthesiae or episodes of distorted sensation, such as pins and needles, tingling, coldness, numbness or burning often accompany the pain [39]. The lower legs can be exquisitely tender to touch, with any disturbance of the hair follicles resulting in excruciating pain. Because pain can be aggravated by repeated contact of the lower limbs with foreign objects, even basic daily activities such as sitting at a desk can be disrupted. Pain often occurs at the onset of the disease and is often worsened by initiation of therapy with insulin or sulphonylureas [43].

It can be associated with profound weight loss and severe depression that has been termed diabetic neuropathic cachexia [44]. This syndrome occurs predominantly in male patients and can occur at any time in the course of both Type I and Type II diabetes. It is self-limiting and invariably responds to simple symptomatic treatment. Conditions such as Fabry's disease, amyloid, HIV infection, heavy metal poisoning (such as arsenic) and excess alcohol consumption should be excluded. It does overlap with the idiopathic variety of acute painful small fibre neuropathy that is also a diagnosis by exclusion [45].

Chronic painful neuropathy. There is another variety of painful polyneuropathy with onset occurring later, often years in the course of the diabetes, in which the pain persists for longer than 6 months and becomes debilitating. This condition can result in tolerance to narcotics and analgesics and finally to addiction. It is extremely resistant to all forms of interven- tion, and most frustrating for both patient and physician.

The mechanism for pain in small-fibre neuropathy is not well understood. Hyperglycaemia can be a factor in lowering the pain threshold. The condition can appear soon after initiation of therapy [43]. A striking reduction of symptoms can be achieved with the intravenous injection of insulin [46]. There is a sequence in diabetic neuropathy, which is when nerve function is good and there is no pain. Progression of the condition results in nerve dysfunction and pain. Disappearance of pain does not necessarily reflect nerve recovery but rather nerve death. When patients report the loss of pain, progression of the neuropathy must be excluded by careful examination.

\section{Large-fibre neuropathies}

Large-fibre neuropathies can involve sensory or motor nerves or both. These tend to be the neuropathies of signs rather than symptoms. Large fibres subserve motor function, vibration perception, position sense and cold thermal perception. Unlike the small nerve fibres these are the myelinated, rapidly conducting fibres that begin in the toes and have their first synapse in the medulla oblongata. They tend to be affected first because of their length and the tendency in diabetes for nerves to "die back". Because they are myelinated, they are the fibres represented in the electromyograph and subclinical abnormalities in nerve function are readily detected. The symptoms can be minimal; sensation of walking on cotton, floors feeling "strange", inability to turn the pages of a book or inability to discriminate among coins.

Most patients with DSPN have, however, a "mixed" variety of neuropathy with both large and small nerve fibre damage. In the case of DSPN, a 
Table 2. Clinical presentation of large-fibre neuropathies

- Impaired vibration perception (often the first objective evidence) and position sense.

- Depressed tendon reflexes.

- A $\delta$ type deep-seated gnawing, dull, like a toothache in the bones of the feet or even crushing or cramp-like pain.

- Sensory ataxia (waddling like a duck).

- Wasting of small muscles of feet with hammertoes (intrinsic minus feet and hands) with weakness of hands and feet.

- Shortening of the achilles tendon with pes equinus.

- Increased blood flow (hot foot).

"glove and stocking" distribution of sensory loss is almost universal [27]. Early in the course of the neuropathic process, multifocal sensory loss also might be found (Table 2). In some patients, severe distal muscle weakness can accompany the sensory loss resulting in an inability to stand on the toes or heels. Some grading systems use this as a definition of severity.

\section{Autonomic neuropathies}

Diabetic autonomic neuropathy can involve any system in the body. It has been said that to know autonomic neuropathy is to know the whole of medicine. Involvement of the autonomic nervous system can occur as early as the first year after diagnosis and major manifestations are cardiovascular, gastrointestinal, and genitourinary system dysfunction [27, 47] (Table 3). Reduced exercise tolerance, oedema, paradoxic supine or nocturnal hypertension and intolerance to heat due to defective thermoregulation are a consequence of autonomic neuropathy. Defective blood flow in the small capillary circulation is found with decreased responsiveness to mental arithmetic, cold pressor, hand grip and heating [42]. The defect is associated with a reduction in the amplitude of vasomotion [48] resembling premature ageing [42]. There are differences in the glabrous and hairy skin circulations. In hairy skin a functional defect is found before the development of neuropathy [49] and is correctable with antioxidants [50]. The clinical counterpart is a dry cold skin, loss of sweating, development of fissures and cracks that are portals of entry for organisms leading to infectious ulcers and gangrenes. Silent myocardial infarction, respiratory failure, amputations and sudden death are hazards for the diabetic patients with cardiac autonomic neuropathy $[23,51]$. Therefore, it is vitally important to make this diagnosis early so that appropriate intervention can be instituted [52].
Table 3. Clinical features of autonomic neuropathies

- Cardiovascular
Resting tachycardia
Orthostatic hypotension
Silent myocardial infarction, congestive heart failure and sud-
den death
- Gastrointestinal
Gastroparesis
Diarrhoea, constipation
- Genitourinary
Bladder dysfunction
Erectile dysfunction
- Peripheral
Gustatory sweating
Pupillary abnormalities
Disturbed neurovascular flow
Oedema
- Metabolic
Hypoglycaemia unawareness, hypoglycaemia unresponsive-
ness

\section{Diagnosis and differential diagnosis of neuropathy}

The diagnosis of diabetic neuropathy rests heavily on a careful history for which a number of questionnaires have been developed by Boulton [4], Dyck [53], Vinik [54] and others [55, 56]. The initial neurologic evaluation should be directed towards the detection of the specific part of the nervous system affected by diabetes (Fig. 5). Bedside neurologic examination is quick and easy but provides nominal or ordinal measures and contains substantial inter-individual and intra-individual variation. For example, it is useless to measure vibration perception with a tuning fork other than one that has a frequency of $128 \mathrm{~Hz}$. Similarly, using a 10-g monofilament is good for predicting foot ulceration, as is the Achilles reflex, but both are insensitive to the early detection of neuropathy and a $1.0-\mathrm{g}$ monofilament increases the sensitivity from 60 to $90 \%$ [57]. Sensory function must be evaluated on both sides of the feet and hands to be sure not to miss entrapment syndromes. A Tinel sign is not only useful for carpal tunnel problems but can be applied to the ulnar notch, the head of the fibula and below the medial tibial epicondyle for ulnar, peroneal and medial plantar entrapments, respectively. The 1988 San Antonio conference on diabetic neuropathy and the 1992 conference of the American Academy of Neurology [10] recommended that at least one variable from each of the following five categories are measured to classify diabetic neuropathy: symptom profiles, neurologic examination, QST, nerve conduction study and autonomic function testing. The least reliable measure is the Neurologic Symptom Score. The QST and QAFT are objective indices of neurologic functional status. Combined, these tests cover vibratory, proprioceptive, tactile, pain, thermal and autonomic function. Recently, development of a 


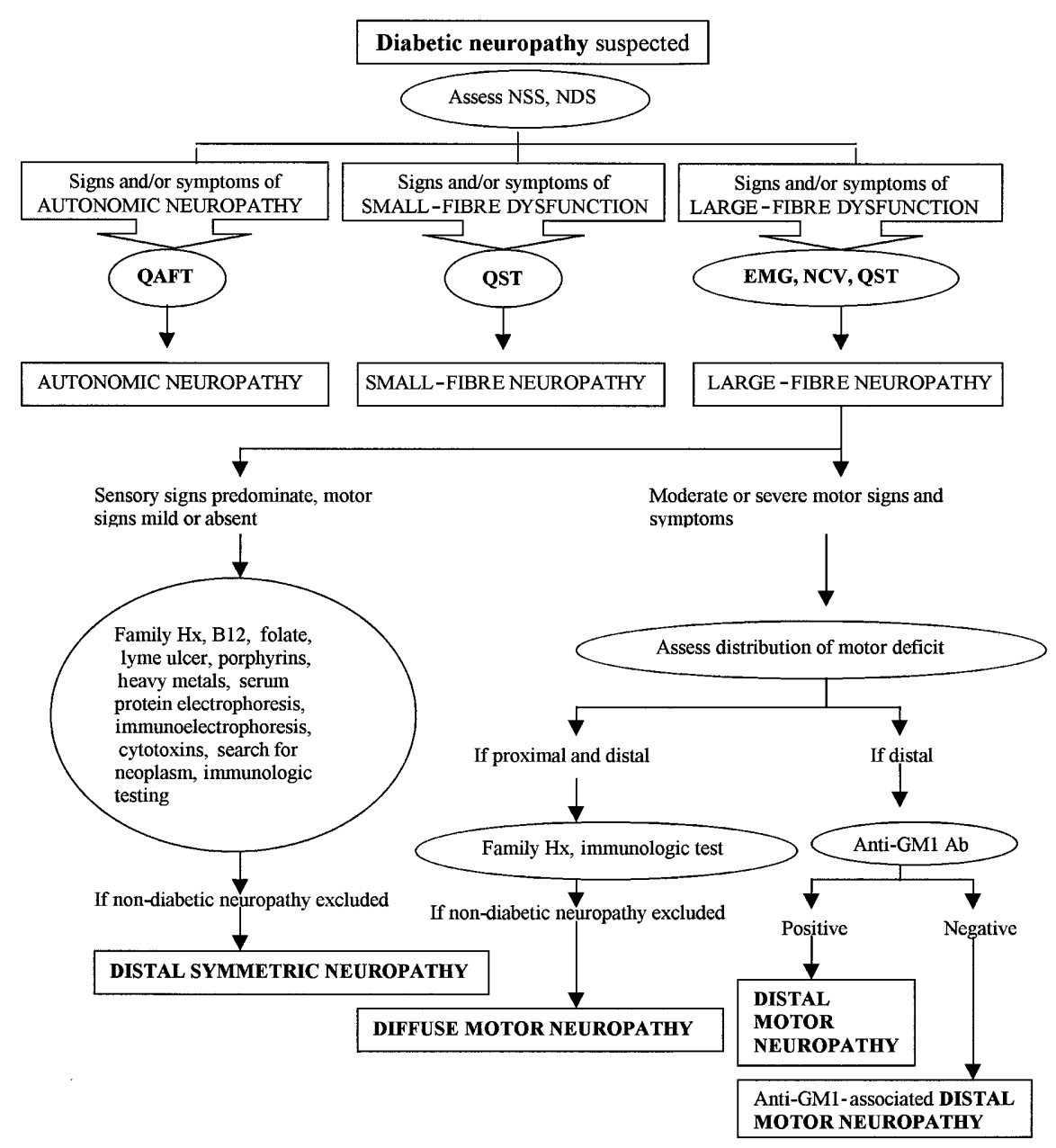

Fig.5. Diagnostic diagrams for assessment of neurologic deficit and classification of neuropathic syndrome. NSS, neurological symptom score; NDS, nerve disability score; EMG, electromyography

number of relatively inexpensive devices have allowed suitable assessment of somatosensory function, including vibration, thermal, light-touch and pain perception [58]. These types of instruments allow cutaneous sensory functions to be assessed noninvasively and their measurements are correlated with specific neural fibre function.

The QAFT consist of a series of simple, non-invasive tests for detecting cardiovascular autonomic neuropathy $[40,59]$. These tests are based on detection of heart rate and blood pressure response to a series of manoeuvres. Specific tests are used in evaluating disordered regulation of gastrointestinal, genitourinary, pseudomotor function and peripheral skin blood flow induced by autonomic diabetic neuropathy [57].

Biopsy of nerve tissue can be helpful for excluding other causes of neuropathy and in the determination of predominant pathologic changes in patients with complex clinical findings as a means of dictating choice of treatment $[34,60]$. Skin biopsy has some clinical advantages in diagnosis of small-fibre neuropathies by quantification of PGP 9.5 when all other measures are negative [20,61]. Diabetes as the cause of neuropathy is diagnosed by exclusion of various other causes of neuropathy $[27,62]$.

\section{Management of neuropathy}

Once neuropathy is diagnosed, therapy can then be instituted with the goal of both reducing symptoms and preventing the progression of neuropathy. Successful management of these syndromes must be geared to the individual pathogenic processes.

\section{Management aimed at pathogenetic mechanisms}

Control of hyperglycaemia. Retrospective and prospective studies have suggested a relation between hyperglycaemia and the development and severity of diabetic neuropathy. Pirart [63] followed 4,400 diabetic patients over 25 years and showed an increase in prevalence of clinically detectable diabetic neuropathy from $12 \%$ of patients at the time of diagnosis of 
diabetes to almost $50 \%$ after 25 years. The highest prevalence occurred in those people with the poorest diabetes control. The DCCT research Group [12] reported statistically significant effects of intensive insulin therapy on prevention of neuropathy. The prevalence rates for clinical or electrophysiologic evidence of neuropathy were reduced by $50 \%$ in those treated by intensive insulin therapy during 5 years. At that stage of the study, only $3 \%$ of the patients in the primary prevention cohort treated by intensive insulin therapy showed minimal signs of diabetic neuropathy, compared with $10 \%$ of those treated by the conventional regime $(p=0.006)$. In the secondary prevention cohort, intensive insulin therapy reduced the prevalence of clinical neuropathy by $56 \%$ (7\% in intensive insulin therapy group vs $16 \%$ in conventional therapy group, $p<0.002)$. The results of the DCCT study support the necessity for strict glycaemic control but the effect of insulin as a growth factor and immunomodulator, apart from its metabolic effects, must also be investigated. In the UKPDS, control of blood glucose was associated with improvement in vibration perception [64-66]. In the recently described Steno trial [67], a reduction of the odds ratio for the development of autonomic neuropathy to 0.32 was reported. This was a stepwise, progressive study that involved treatment of Type II diabetic patients with hypotensive drugs, including angiotensin-converting enzyme (ACE) inhibitors, $\mathrm{Ca}^{2+}$ channel antagonists, hypoglycaemic agents, aspirin, hypolipidaemic agents, and antioxidants. These findings argue strongly for the multifactorial nature of neuropathy and for the need to address the multiple metabolic abnormalities.

Aldose reductase inhibitors (ARIs). Aldose reductase inhibitors reduce the flux of glucose through the polyol pathway, inhibiting tissue accumulation of sorbitol and fructose and preventing reduction of redox potentials. In a placebo-controlled double-blind study of Tolrestat, 219 diabetic patients with symmetrical polyneuropathy, as defined by at least one pathologic cardiovascular reflex, were treated for 1 year [68]. Patients who received Tolrestat showed improvement in autonomic function tests, as well as in vibration perception whereas placebo-treated patients showed deterioration in most of the variables measured $(p<0.05)$ [69]. It has now been shown that there is a dose-dependent improvement in nerve fibre density, particularly small unmyelinated nerve fibres, in a 12month study of Zenarestat [70]. This was accompanied by an increase in nerve conduction velocity, albeit the changes in NCV occurred at a dose of the drug that did not change the nerve fibre density [70]. Impaired cardiac ejection fractions can be improved with Zopolrestat [71]. The promise shown with the newer ARIs is being exploited by at least two other companies and research studies are being done on an array of new ARIs. It is also becoming clear that aldose reductase inhibition could be insufficient in its own right to achieve the desirable degree of metabolic enhancement in patients with a multitude of biochemical abnormalities. Combinations of therapy with ARIs and antioxidants could become critical if we are to abate the relentless progress of diabetic neuropathy.

Alpha-lipoic acid. Lipoic acid (1,2-dithiolane-3-pentanoic acid), a derivative of octanoic acid, is present in food and is also synthesised by the liver. It is a natural cofactor in the pyruvate dehydrogenase complex where it binds acyl groups and transfers them from one part of the complex to another $\alpha$-lipoic acid which, also known as thioctic acid, has generated considerable interest as a thiol replenishing and redox modulating agent. It has been shown to be effective in reducing both the somatic and autonomic neuropathies in diabetes [72-74]. It is currently undergoing extensive trials in the United States as both an antidiabetic agent and for the treatment of diabetic neuropathy.

Gamma-linolenic acid (GLA). Linoleic acid, an essential fatty acid, is metabolised to dihomo- $\gamma$-linolenic acid, which serves as an important constituent of neuronal membrane phospholipids, and also serves as a substrate for prostaglandin $\mathrm{E}$ formation, seemingly important for preservation of nerve blood flow. In diabetes, conversion of linoleic acid to $\gamma$-linolenic acid and subsequent metabolites is impaired, possibly contributing to the pathogenesis of diabetic neuropathy [75]. A recent multicentre double-blind placebocontrolled trial using GLA for 1 year showed improvements in both clinical measures and electrophysiologic testing $(p<0.05)[76]$.

Aminoguanidine. Animal studies using aminoguanidine, an inhibitor of the formation of advanced glycation end products (AGE), show improvement in nerve conduction velocity in streptozotocin-induced diabetic neuropathy in rats. Controlled clinical trials to determine its efficacy in humans [77, 78] have been discontinued because of toxicity. There are, however, successors to aminoguanidine that hold promise for this approach [79].

Human intravenous immunoglobulin (i.v. Ig). Immune intervention with i.v. Ig has become appropriate in some patients with forms of peripheral diabetic neuropathy that are associated with signs of anti-neuronal autoimmunity $[35,38]$. Treatment with immunoglobulin is well tolerated and is considered safe, especially with respect to viral transmission [80]. The major toxicity of i.v. Ig has been an anaphylactic reaction but the frequency of these reactions is now low and confined mainly to patients with immunoglobulin 
(usually $\operatorname{Ig} \mathrm{A}$ ) deficiency. Patients can experience severe headache due to aseptic meningitis, which resolves spontaneously. In some instances, it is necessary to combine treatment with prednisone or azathioprine or both. Relapses can occur requiring repeated courses of therapy.

Neurotrophic therapy. There is now considerable evidence in animal models of diabetes that decreased expression of nerve growth factor (NGF) and its receptors, e.g. trk A reduces retrograde axonal transport of NGF and diminishes support of small unmyelinated neurons and their neuropeptides, such as substance $\mathrm{P}$ and calcitonin gene-related peptide (CGRP), both potent vasodilators [81-83]. Furthermore, recombinant human NGF (rhNGF) treatment restores these neuropeptide concentrations towards normal and prevents the manifestations of sensory neuropathy in animals [84]. In a 15-centre, doubleblind, placebo-controlled study of the safety and efficacy of rhNGF in 250 subjects with symptomatic small-fibre neuropathy [16], rhNGF improved the neurologic impairment score of the lower limbs and improved the small-nerve fibre function cooling threshold (A $\delta$-fibres) and the ability to perceive heat pain (C-fibre) compared with placebo. These results were consistent with the postulated actions of NGF on trk A receptors present on small-fibre neurons. This led to two large multicentre studies conducted in the United States and the rest of the world. Results of these two studies were presented at the ADA meetings in June 1999 [17]. Regrettably, rhNGF was not found to have beneficial effects over and above placebo. The reason for this dichotomy has not been resolved but this has somewhat dampened the enthusiasm for growth factor therapy of diabetic neuropathy.

\section{Management aimed at symptoms}

Pain control. Control of pain is one of the most difficult management issues in diabetic neuropathy. In essence, simple measures are tried first (Fig. 6). If no distinction is made for pain syndromes then the numbers needed to treat (NNT) to reduce pain by $50 \%$ is 1.4 for optimal dose tricyclic antidepressants, 1.9 for dextromethorphan, 3.3 for carbamazepine, 3.4 for tramadol, 3.7 for gabapentin, 5.9 for capsaicin, 6.7 for selective serotonin re-uptake inhibitors and 10.0 for mexiletine [85]. If pain is, however, divided according to its derivation from different nerve fibre type (A $\delta$ vs C-fibre), different types of pain respond to different therapies (Fig. 6), as described below.

\section{C-fiber pain.}

Initially, when there is ongoing damage to the nerves, patients experience the pain of the burning, lancinat-

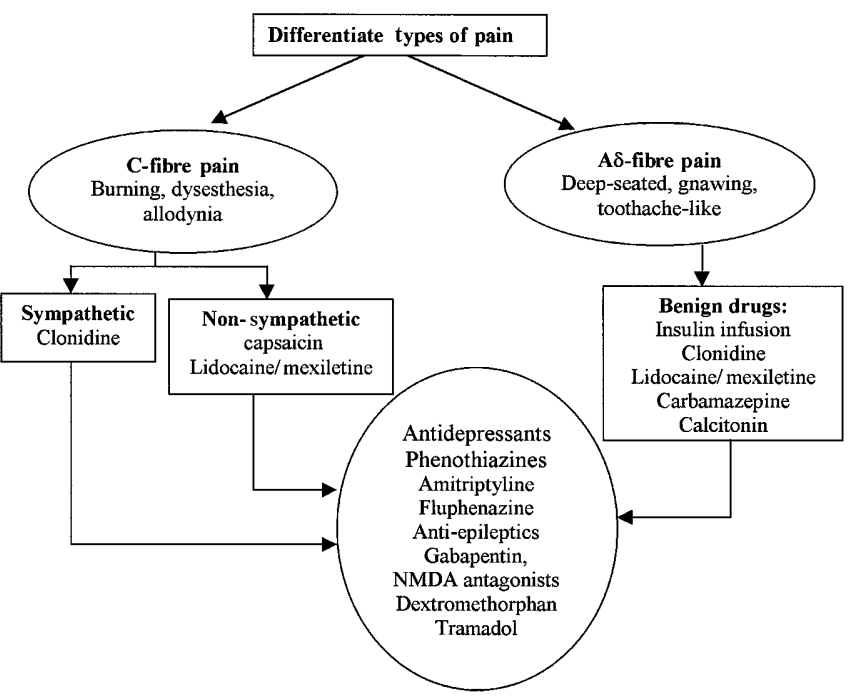

Fig. 6. Management of painful diabetic neuropathy

ing, dysesthetic type often accompanied by hyperalgesia and allodynia (Table 4). Because the peripheral sympathetic nerve fibres are also small unmyelinated C-fibres, sympathetic blocking agents (clonidine) can lessen the pain. Loss of sympathetic regulation of sweat glands and $\mathrm{A}-\mathrm{V}$ shunt vessels in the foot creates a favourable environment for bacteria to penetrate, multiply and wreak havoc with the foot. These fibres use the neuropeptide substance $\mathrm{P}$ as their neurotransmitter and depletion of axonal substance $\mathrm{P}$ (capsaicin) will often lead to lessening of the pain. When the destructive forces persist, however, the patient becomes pain free and develops impaired warm temperature and pain thresholds. Disappearance of pain in these circumstances should be hailed as a warning that the neuropathy is progressing.

Capsaicin. Capsaicin is extracted from chilli peppers and a simple cheap mixture is one to three teaspoons

Table 4. Managing small-fibre neuropathies

- Patients must be instructed on foot care with daily foot inspection

- They must have a mirror in the bathroom for inspection of the soles of the feet

- Providing patients with a monofilament for self-testing reduces ulcers

- All diabetes patients should wear padded socks

- Shoes must fit well with adequate support and must be inspected for the presence of foreign bodies (e.g. nails, pins, teeth etc) before dressing, i.e. examine the feet and the shoes daily

- Patients must exercise care with exposure to heat (no falling asleep in front of fires)

- Emollient creams should be used for the drying and cracking

- After bathing feet should be thoroughly dried and powdered between the toes

- Nails should be cut transversely, preferably by a chiropodist 
of cayenne pepper added to a jar of cold cream which can be applied to the area of pain. It has high selectivity for a subset of sensory neurons which have been identified as unmyelinated C-fibre afferent or thin-myelinated (A $\delta$ ) fibres. Prolonged application of capsaicin depletes stores of substance $\mathrm{P}$ and possibly other neurotransmitters from sensory nerve endings. This reduces or abolishes the transmission of painful stimuli from the peripheral nerve fibres to the higher centres [86]. Care must be taken to avoid eyes and genitals and gloves must be worn. Because of capsaicin's volatility it is safer to cover affected areas with plastic wrap. There is initial exacerbation of symptoms followed by relief in 2 to 3 weeks.

Clonidine. There is an element of sympathetic-mediated C-fibre type pain that can be overcome with clonidine $\left(\alpha_{2}\right.$-adrenergic agonist) or phentolamine. Clonidine can be applied topically [87] but the dose titration can be more difficult. If clonidine fails, the local anaesthetic agent, mexiletine warrants a trial. Unresponsive patients are treated as outlined in Fig. 6.

\section{Ad-fibre pain.}

$\mathrm{A} \delta$-fibre pain is a more deep-seated, dull and gnawing ache, which often does not respond to the measures described previously. A number of different agents have been used for the pain associated with these fibres with varying success.

Insulin. Continuous intravenous insulin infusion without resort to lowering blood glucose concentration can be useful in these patients. A response with reduction of pain usually occurs within $48 \mathrm{~h}$ [46] and the insulin infusion can be discontinued. If this measure fails there are several medications available that can abolish the pain.

Nerve blocking. Lidocaine, given by slow infusion, has been shown to provide relief of intractable pain for 3 to 21 days. This form of therapy can be of most use in self-limited forms of neuropathy. If successful, therapy can be continued with oral mexiletine. These compounds target the pain caused by hyperexcitability of superficial, free nerve endings [88].

Tramadol and dextromethorphan. There are two possible targeted therapies. Tramadol is a centrally acting analgesic for use in treating moderate to severe pain. It has recently been reported to provide pain relief in diabetic neuropathy [89]. Another spinal cord target for pain relief is the excitatory glutaminergic $N$-methyl-D-aspartate (NMDA) receptor. Blockade of NMDA receptors is believed to be one mechanism by which dextromethorphan exerts analgesic efficacy [90]. An accomplished pharmacist can procure a sugar-free solution of dextromethorphan.
Antidepressants. Clinical trials have focused on interrupting pain transmission using antidepressant drugs that inhibit the re-uptake of norepinephrine or serotonin. This central action accentuates the effects of these neurotransmitters in activation of endogenous pain-inhibitory systems in the brain that modulate pain-transmission cells in the spinal cord [91]. Side effects, including dysautonomia and dry mouth, can be troublesome. Switching to nortriptyline can lessen some of the anticholinergic effects of amitriptyline.

Carbamazepine. Several double-blind placebo-controlled studies have shown carbamazepine to be effective in the management of pain in diabetic neuropathy [27]. Toxic side effects can limit its use in some patients. It is, however, very useful for those patients with lightning or shooting pain.

Phenytoin. Diphenylhydantoin has long been used in the treatment of painful neuropathies. Double-blind cross-over studies do not show a therapeutic benefit of phenytoin compared with placebo in diabetic neuropathy [92]. Also, side effects mitigate its use in people with diabetes. Its ability to suppress insulin secretion has resulted in precipitation of hyperosmolar diabetic coma.

Gabapentin. Gabapentin is an effective anticonvulsant whose mechanism is not well understood, yet holds additional promise as an analgesic agent in painful neuropathy [93]. In a multicentre study in the United States [94], gabapentin monotherapy seemed to be efficacious for the treatment of pain and sleep interference associated with diabetic peripheral neuropathy. It also has positive effects on mood and quality of life [95].

Transcutaneous nerve stimulation (electrotherapy). Transcutaneous nerve stimulation (electrotherapy) occasionally can be helpful and is certainly one of the more benign therapies for painful neuropathy [96]. Care should be taken to move the electrodes around to identify sensitive areas and obtain maximum relief.

Analgesics. Analgesics are rarely of much benefit in the treatment of painful neuropathy, although they can be of some use on a short-term basis for some of the self-limited syndromes, such as painful diabetic third-nerve palsy. Use of narcotics in the setting of chronic pain generally is avoided because of the risk of addiction.

Calcitonin. In a placebo-controlled study, ten patients with painful diabetic neuropathy were treated with $100 \mathrm{U}$ of calcitonin a day. About $39 \%$ of the patients had near-complete relief of symptoms. The improvement was seen after only 2 weeks of treatment [97]. 
Table 5. Management of large-fibre neuropathies

- Gait and strength training

- Pain management as detailed above

- Orthotics should be fitted with proper shoes for the deformities

- Tendon lengthening for Achilles tendon shortening

- Bisphophonates can be given for osteopenia

- Surgical reconstruction and full length casting as necessary

\section{Management of large-fibre neuropathies}

Patients with large-fibre neuropathies are incoordinate and ataxic. As a result, they are more likely to fall than non-neuropathic age-matched people [98]. It has recently been shown that high-intensity strength training in older people increases muscle strength in a variety of muscles. More importantly, the strength training resulted in improved coordination and balance quantifiable with backward tandem walking [99] (Table 5). Thus it is vital to embark on a programme of strength training and improvement of balance.

\section{Management of autonomic neuropathy}

Prevention and reversibility of autonomic neuropathy. It has now become clear that strict glycaemic control [13] and a stepwise progressive management of hyperglycaemia, lipids, blood pressure and use of antioxidants [73] and ACE inhibitors [100] reduce the odds ratio for autonomic neuropathy to 0.32 [67]. It has also been shown that mortality is a function of loss of beat-to-beat variability with MI. This can be reduced by $33 \%$ with short-term treatment with insulin [101]. Successful pancreas transplantation has been reported to improve epinephrine response and restore hypoglycaemia symptom recognition to normal in patients with long-standing diabetes and established autonomic neuropathy [102]. In patients with early cardiac autonomic neuropathy a reversible metabolic component of this neuropathy has been shown to exist [103].

\section{Postural hypotension.}

The syndrome of postural hypotension is posture-related dizziness and syncope. Patients who have Type II diabetes and orthostatic hypotension are hypovolaemic and have sympathoadrenal insufficiency; both factors contribute to the pathogenesis of orthostatic hypotension [104]. Postural hypotension in the patient with diabetic autonomic neuropathy can present a difficult management problem. Increasing the blood pressure in the standing position must be balanced against preventing hypertension in the supine position.
Supportive garments. Whenever possible, attempts should be made to increase venous return from the periphery using total body stockings. Leg compression alone is, however, less effective, presumably reflecting the large capacity of the abdomen relative to the legs [105]. Patients should be instructed to put them on while lying down and not remove them until returning to the supine position.

Drug therapy. Some patients with postural hypotension can benefit from treatment with 9-aflurohydrocortisone. Unfortunately, symptoms do not improve until oedema occurs, and there is a risk of developing congestive heart failure and hypertension. If fluorohydrocortisone does not work satisfactorily, various adrenergic agonists and antagonists can be used. If the adrenergic receptor status is known, then therapy can be guided to the appropriate agent. Metoclopramide can be helpful in patients with dopamine excess or increased sensitivity to dopaminergic stimulation. Patients with $\alpha_{2}$-adrenergic receptor excess might respond to the $\alpha_{2}$-antagonist yohimbine. Those few patients in whom $\beta$-receptors are increased can be helped with propranolol. A deficiency of $\alpha_{2}$-adrenergic receptor can be treated with the $\alpha_{2}$-agonist, clonidine, which in this setting can paradoxically increase blood pressure. Small doses should be given to start with and the dose increased gradually. If the preceding measures fail, midodrine, an $\alpha_{1}$-adrenergic agonist or dihydroergotamine in combination with caffeine might help. A particularly refractory form of postural hypotension occurs in some patients postprandially and can respond to therapy with octreotide given subcutaneously in the mornings.

\section{Gastropathy.}

Gastrointestinal motor disorders are frequent and widespread in Type II diabetic patients, regardless of symptoms [106] and there is a poor correlation between symptoms and objective evidence of a functional or organic defects. The first step in management of diabetic gastroparesis consists of multiple, small feedings. The amount of fat should be decreased because it tends to delay gastric emptying. Maintenance of glycaemic control is important [107, 108]. Metoclopramide can be used. Cisapride and domperidone $[109,110]$ has been shown to be effective in some patients, although probably no more so than metoclopramide. Erythromycin given as either a liquid or suppository also can be helpful. Erythromycin acts on the motilin receptor, "the sweeper of the gut", and shortens gastric emptying time [111]. If medications fail and severe gastroparesis persists, jejunostomy placement into normally functioning bowel could be needed. 


\section{Enteropathy.}

Enteropathy involving the small bowel and colon can produce both chronic constipation and explosive diabetic diarrhoea, making treatment of this particular complication difficult.

Antibiotics. Stasis of bowel contents with bacterial overgrowth can contribute to the diarrhoea. Treatment with broad-spectrum antibiotics is the mainstay of therapy, including tetracycline or trimethoprim and sulphamethoxazole. Metronidazole seems to be the most effective and should be continued for at least 3 weeks.

Cholestyramine. Retention of bile can occur and can be highly irritating to the gut. Chelation of bile salts with cholestyramine $4 \mathrm{~g}$ three times a day mixed with fluid can offer relief of symptoms.

Diphenoxylate plus atropine. Diphenoxylate plus atrophine can help to control the diarrhoea. Toxic megacolon can, however, occur and extreme care should be used.

Diet. Patients with poor digestion can benefit from a gluten-free diet. Beware of certain fibres in the neuropathic patient that can lead to bezoar formation because of bowel stasis in gastroparetic or constipated patients.

Cystopathy.

Patients with neurogenic bladder should be instructed to palpate their bladders and, if they are unable to initiate micturition when their bladders are full, use Crede's manoeuvre to start the flow of urine. Parasympathomimetics such as bethanechol are sometimes helpful, although they frequently do not help to fully empty the bladder. Extended sphincter relaxation can be achieved with an $\alpha_{1}$-blocker, such as doxazosin [27]. Self-catheterisation can be particularly useful in this setting, with the risk of infection generally being low.

\section{Sexual dysfunction.}

Erectile dysfunction (ED) occurs in $50-75 \%$ of diabetic men and it tends to occur at an earlier age than in the general population. The incidence of ED in diabetic men aged $20-29$ years is $9 \%$ and increases to $95 \%$ by age 70 . It can be the presenting symptom of diabetes. More than $50 \%$ notice the onset of ED within 10 years of the diagnosis but it can precede the other complications of diabetes. The aetiology of ED in diabetes is multifactorial. Neuropathy, vascular disease, diabetes control, nutrition, endocrine disorders, psychogenic factors as well as drugs used in the treatment of diabetes and its complications play a part $[112,113]$. The diagnosis of the cause of ED is made by a logical stepwise progression $[112,113]$ in all instances. An approach to therapy has recently been presented $[112,114]$.

\section{Gustatory sweating.}

Gustatory sweating is more common than previously believed and topically applied glycopyrrolate is very effective treatment in reducing both the severity and frequency $[115,116]$.

\section{Diabetic neuropathies: prospects for the future}

Management of diabetic neuropathy encompasses a wide variety of therapies. Treatment must be adjusted individually in a manner that addresses the particular manifestation, underlying pathogenesis, of each patient's unique clinical presentation, without subjecting the patient to untoward medication effects. There are new areas being explored in an attempt to enhance blood flow through vasa nervorum, such as the prostacyclin analogue beraprost, blockade of thromboxane $\mathrm{A}_{2}$ and drugs that restore $\mathrm{Na} / \mathrm{K}$-ATPase activity to normal such as cilostazol, a potent phosphodiesterase inhibitor, and $\alpha$-lipoic acid. These have, however, not reached the clinical area.

\section{Summary}

Diabetic neuropathy is a common complication of diabetes that is often associated both with considerable morbidity and mortality. The epidemiology and natural course of diabetic neuropathy is clouded with uncertainty, largely due to confusion regarding the definition and measurement of this disorder.

The recent resurgence of interest in the vascular hypothesis, oxidative stress, the neurotrophic hypothesis and the possibility of the role of autoimmunity have opened up new avenues of investigation for therapeutic intervention. Paralleling our increased understanding of the pathogenesis of diabetic neuropathy, there must be refinements in our ability to measure quantitatively the different types of defects that occur in this disorder, so that appropriate therapies can be targeted to specific fibre types. These tests must be validated and standardised to allow comparability between studies and a more meaningful interpretation of study results. Our ability to manage successfully the many different manifestations of diabetic neuropathy depends ultimately on our success in uncovering the pathogenic processes underlying this disorder. 


\section{References}

1. Vinik AI, Mitchell BD, Leichter SB, Wagner AL, O'Brian JT, Georges LP (1995) Epidemiology of the Complications of Diabetes. In: Leslie RDG, Robbins DC (eds) Diabetes: Clinical Science in Practice. Cambridge University Press, Cambridge, pp 221-287

2. Holzer SE, Camerota A, Martens L, Cuerdon T, CrystalPeters J, Zagari M (1998) Costs and duration of care for lower extremity ulcers in patients with diabetes. Clin Ther 20: 169-181

3. Caputo GM, Cavanagh PR, Ulbrecht JS, Gibbons GW, Karchmer AW (1994) Assessment and management of foot disease in patients with diabetes. N Engl J Med 331: 854-860

4. Young MJ, Boulton AJM, MacLeod AF, Williams DRR, Sonksen PH (1993) A multicentre study of the prevalence of diabetic peripheral neuropathy in the United Kingdom hospital clinic population. Diabetologia 36: $1-5$

5. Dyck PJ, Kratz KM, Karnes JL et al. (1993) The prevalence by staged severity of various types of diabetic neuropathy, retinopathy, and nephropathy in a populationbased cohort: The Rochester Diabetic Neuropathy Study. Neurology 43: 817-824

6. Vinik A (1999) Diabetic neuropathy: pathogenesis and therapy. Am J Med 107: 17S-26S

7. Armstrong DG, Lavery LA, Harkless LB (1998) Validation of a diabetic wound classification system. The contribution of depth, infection, and ischemia to risk of amputation. Diabetes Care 21: 855-859

8. Levitt NS, Stansberry KB, Wychanck S, Vinik AI (1996) Natural progression of autonomic neuropathy and autonomic function tests in a cohort of IDDM. Diabetes Care 19: 751-754

9. Rathmann W, Ziegler D, Jahnke M, Haastert B, Gries FA (1993) Mortality in diabetic patients with cardiovascular autonomic neuropathy. Diabet Med 10: 820-824

10. Consensus Statement (1988) Report and recommendations of the San Antonio conference on diabetic neuropathy. American Diabetes Association American Academy of Neurology. Diabetes Care 11: 592-597

11. Watkins PJ (1993) Progression of diabetic autonomic neuropathy. Diabet Med 10[Suppl 2]:77S-78S

12. DCCT Research Group (1993) The effect of intensive treatment of diabetes on the development and progression of ling-term complications in insulin-dependent diabetes mellitus. N Engl J Med 329: 977-986

13. DCCT Research Group (1995) The effect of intensive diabetes therapy on the development and progression of neuropathy. Ann Intern Med 122: 561-568

14. Ziegler D, Cicmir I, Mayer P, Wiefels K, Gries FA (1988) Somatic and autonomic nerve function during the first year after diagnosis of type 1 (insulin-dependent) diabetes. Diabetes Res 7: 123-127

15. Partanen J, Niskanen L, Lehtinen J, Mervaala E, Siitonen O, Uusitupa M (1995) Natural history of peripheral neuropathy in patients with non-insulin-dependent diabetes mellitus. N Engl J Med 333: 89-94

16. Apfel SC, Kessler JA, Adornato BT et al. (1998) Recombinant human nerve growth factor in the treatment of diabetic polyneuropathy. Neurology 51: 695-702

17. Vinik AI (1999) Treatment of diabetic polyneuropathy (DPN) with recombinant human nerve growth factor (rhNGF). Diabetes 48[Suppl 1]:A54-A55 (Abstract)

18. Dyck PJ, Kratz KM, Lehman KA et al. (1991) The Rochester Diabetic Neuropathy Study: design, criteria for types of neuropathy, selection bias, and reproducibility of neuropathic tests. Neurology 41: 799-807

19. Oh SJ (1993) Clinical Electromyelography: Nerve conduction studies. In: Oh SJ (ed) Nerve conduction in polyneuropathies. Williams \& Wilkins, Baltimore, pp 579-591

20. Kennedy WR, Wendelschafer-Crabb G, Johnson T (1996) Quantitation of epidermal nerves in diabetic neuropathy. Neurology 47: 1042-1048

21. Herrmann DN, Griffin JW, Hauer P, Cornblath DR, McArthur JC (1999) Epidermal nerve fiber density and sural nerve morphometry in peripheral neuropathies. Neurology 53: 1634-1640

22. Karamitsos DT, Didangelos TP, Athyros VG, Kontopoulos AG (1998) The natural history of recently diagnosed autonomic neuropathy over a period of 2 years. Diabetes Res Clin Pract 42: 55-63

23. Ziegler D (1994) Diabetic cardiovascular autonomic neuropathy: prognosis, diagnosis and treatment. Diabetes Metab Rev 10: 339-383

24. Sima AAF, Sugimoto K (1999) Experimental diabetic neuropathy: an update. Diabetologia 42: 773-788

25. Zochodne DW (1999) Diabetic neuropathies: features and mechanisms. Brain Pathol 9: 369-391

26. Greene DA, Stevens MJ, Obrosova I, Feldman EL (1999) Glucose-induced oxidative stress and programmed cell death in diabetic neuropathy. Eur J Pharmacol 375: 217-223

27. Vinik AI, Holland MT, LeBeau JM, Liuzzi FJ, Stansberry KB, Colen LB (1992) Diabetic neuropathies. Diabetes Care 15: 1926-1975

28. Vinik AI, Suwanwalaikorn S (1997) Autonomic Neuropathy. In: DeFronzo RA (ed) Current Therapy of Diabetes Mellitus. Mosby-Year Book, St Louis, pp 165-176

29. Dawson DM (1993) Entrapment neuropathies of the upper extremities. N Engl J Med 329: 2013-2018

30. Llewelyn JG, Thomas PK, King RH (1998) Epineurial microvasculitis in proximal diabetic neuropathy. J Neurol 245: 159-165

31. Vinik AI, Pittenger GL, Milicevic Z, Knezevic-Cuca J (1999) Autoimmune Mechanisms in the Pathogenesis of Diabetic Neuropathy. In: Eisenbarth RG (ed) Molecular Mechanisms of Endocrine and Organ Specific Autoimmunity. Landes Company, Georgetown, pp 217-251

32. Steck AJ, Kappos L (1994) Gangliosides and autoimmune neuropathies: classification and clinical aspects of autoimmune neuropathies. J Neurol Neurosurg Psychiatry 57[Suppl]:26-28

33. Sander HW, Chokroverty S (1996) Diabetic amyotrophy: current concepts. Semin Neurol 16: 173-178

34. Said G, Goulon-Goreau C, Lacroix C, Moulonguet A (1994) Nerve biopsy findings in different patterns of proximal diabetic neuropathy. Ann Neurol 35: 559-569

35. Krendel DA, Costigan DA, Hopkins LC (1995) Successful treatment of neuropathies in patients with diabetes mellitus. Arch Neurol 52: 1053-1061

36. Britland ST, Young RJ, Sharma AK, Clarke BF (1992) Acute and remitting painful diabetic polyneuropathy: a comparison of peripheral nerve fibre pathology. Pain 48: 361-370

37. Milicevic Z, Newlon PG, Pittenger GL, Stansberry KB, Vinik AI (1997) Anti-ganglioside GM1 antibody and distalsymmetric "diabetic polyneuropathy" with dominant motor features. Diabetologia 40: 1364-1365

38. Barada A, Reljanovic M, Milicevic Z et al. (1999) Proximal Diabetic Neuropathy-Response To Immunotherapy. Diabetes 48[Suppl 1]: A148 (Abstract) 
39. Bird SJ, Brown MJ (1996) The clinical spectrum of diabetic neuropathy. Semin Neurol 16: 115-122

40. Hanson PH, Schumaker P, Debugne TH, Clerin M (1992) Evaluation of somatic and autonomic small fibers neuropathy in diabetes. Am J Phys Med Rehabil 71: 44-47

41. McArthur JC, Stocks EA, Hauer P, Cornblath DR, Griffin JW (1998) Epidermal nerve fiber density: normative reference range and diagnostic efficiency. Arch Neurol 55: $1513-1520$

42. Stansberry KB, Hill MA, Shapiro SA, McNitt PM, Bhatt BA, Vinik AI (1997) Impairment of peripheral blood flow responses in diabetes resembles an enhanced aging effect. Diabetes Care 20: 1711-1716

43. Tesfaye S, Malik R, Harris N et al. (1996) Arterio-venous shunting and proliferating new vessels in acute painful neuropathy of rapid glycaemic control (insulin neuritis). Diabetologia 39: 329-335

44. Van Heel DA, Levitt NS, Winter TA (1998) Diabetic neuropathic cachexia: the importance of positive recognition and early nutritional support. Int J Clin Pract 52: 591-592

45. Holland NR, Crawford TO, Hauer P, Cornblath DR, Griffin JW, McArthur JC (1998) Small-fiber sensory neuropathies: clinical course and neuropathology of idiopathic cases. Ann Neurol 44: 47-59

46. Said G, Bigo A, Ameri A et al. (1998) Uncommon earlyonset neuropathy in diabetic patients. J Neurol 245: 61-68

47. Zola BE, Vinik AI (1992) Effects of autonomic neuropathy associated with diabetes mellitus on cardiovascular function. Coron Artery Dis 3: 33-41

48. Stansberry KB, Shapiro SA, Hill MA, McNitt PM, Meyer MD, Vinik AI (1996) Impaired peripheral vasomotion in diabetes. Diabetes Care 19: 715-721

49. Stansberry KB, Peppard HR, Babyak GP, Popp G, McNitt PM, Vinik AI (1999) Primary nociceptive afferents mediate the blood flow dysfunction in non-glabrous (hairy) skin of type 2 diabetes. Diabetes Care 22: 1549-1554

50. Haak ES, Usadel KH, Kohleisen M, Yilmaz A, Kusterer K, Haak T (1999) The effect of alpha-lipoic on the neurovascular reflex arc in patients with diabetic neuropathy assessed by capillary microscopy. Microvasc Res 58: 28-34

51. Valensi P (1998) Diabetic autonomic neuropathy: what are the risks? Diabetes Metab 24: 66-72

52. Mancia G, Paleari F, Parati G (1997) Early diagnosis of diabetic autonomic neuropathy: present and future approaches. Diabetologia 40: 482-484

53. Dyck PJ (1988) Detection, characterization and staging of polyneuropathy: assessed in diabetes. Muscle Nerve 11: 21-32

54. Vinik AI, Mitchell B (1988) Clinical aspects of diabetic neuropathies. Diabetes Metab Rev 4: 223-253

55. Ziegler D, Hanefeld M, Ruhnau KJ et al. (1995) Treatment of symptomatic diabetic peripheral neuropathy with the anti-oxidant alpha-lipoic acid. A 3-week multicentre randomized controlled trial (ALADIN Study). Diabetologia 38: 1425-1433

56. Feldman EL, Stevens MJ, Thomas PK, Brown MB, Canal N, Greene DA (1994) A practical two-step quantitative clinical and electrophysiological assessment for the diagnosis and staging of diabetic neuropathy. Diabetes Care 17: $1281-1289$

57. Vinik AI, Newlon P, Milicevic Z, McNitt P, Stansberry KB (1996) Diabetic neuropathies: An overview of clinical aspects. In: LeRoith D, Taylor SI, Olefsky JM (eds) Diabetes Mellitus: A fundamental and clinical text. LippincotRaven, Philadelphia, pp 737-751
58. Vinik AI, Suwanwalaikorn S, Stansberry KB, Holland MT, McNitt PM, Colen LE (1995) Quantitative measurement of cutaneous perception in diabetic neuropathy. Muscle Nerve 18: 574-584

59. Ducher M, Thivolet C, Cerutti C et al. (1999) Noninvasive exploration of cardiac autonomic neuropathy. Diabetes Care 22: 388-393

60. Jaradeh SS, Prieto TE, Lobeck LJ (1999) Progressive polyradiculoneuropathy in diabetes: correlation of variables and clinical outcome after immunotherapy. J Neurol Neurosurg Psychiatry 67: 607-612

61. Periquet MI, Novak V, Collins MP et al. (1999) Painful sensory neuropathy: prospective evaluation using skin biopsy. Neurology 53: 1641-1647

62. Krendel DA, Zacharias A, Younger DS (1997) Autoimmune diabetic neuropathy. Neurol Clin 15: 959-971

63. Pirart J (1977) Diabetes mellitus and its degenerative complications: a prospective study of 4,400 patients observed between 1947 and 1973 (3rd and last part) (author's transl). Diabetes Metab 3: 245-256

64. UK Prospective Diabetes Study (UKPDS) Group (1998) Effect of intensive blood-glucose control with metformin on complications in overweight patients with type 2 diabetes (UKPDS 34). Lancet 352: 854-865

65. UK Prospective Diabetes Study (UKPDS) Group (1998) Intensive blood-glucose control with sulphonylureas or insulin compared with conventional treatment and risk of complications in patients with type 2 diabetes (UKPDS 33). Lancet 352: 837-853

66. UK Prospective Diabetes Study Group (1998) Tight blood pressure control and risk of macrovascular and microvascular complications in type 2 diabetes: UKPDS 38. BMJ 317: 703-713

67. Gaede P, Vedel P, Parving HH, Pedersen O (1999) Intensified multifactorial intervention in patients with type 2 diabetes mellitus and microalbuminuria: the Steno type 2 randomised study. Lancet 353: 617-622

68. Boulton AJM, Levin S, Comstock J (1990) A multicentre trial of the aldose reductase inhibitor tolrestat in patients with symptomatic diabetic neuropathy. Diabetologia 33: 431-437

69. Didangelos TP, Karamitsos DT, Athyros VG, Kourtoglou GI (1998) Effect of aldose reductase inhibition on cardiovascular reflex tests in patients with definite diabetic autonomic neuropathy. J Diabetes Complications 12: 201-207

70. Greene DA, Arezzo JC, Brown MB (1999) Effect of aldose reductase inhibition on nerve conduction and morphometry in diabetic neuropathy. Zenarestat Study Group. Neurology 53: 580-591

71. Johnson BF, Law G, Nesto R et al. (1999) Aldose reductase inhibitor zopolrestat improves systolic function in diabetics. Diabetes 48[Suppl 1]: A133 (Abstract)

72. Ziegler D, Schatz H, Conrad F, Gries FA, Ulrich H, Reichel G (1997) Effects of treatment with the antioxidant alpha-lipoic acid on cardiac autonomic neuropathy in NIDDM patients. A 4-month randomized controlled multicenter trial (DEKAN Study). Deutsche Kardiale Autonome Neuropathie. Diabetes Care 20: 369-373

73. Ziegler D, Gries FA (1997) Alpha-lipoic acid in the treatment of diabetic peripheral and cardiac autonomic neuropathy. Diabetes 46[Suppl 2]: S62-S66

74. Ziegler D, Hanefeld M, Ruhnau KJ et al. (1999) Treatment of symptomatic diabetic polyneuropathy with the antioxidant alpha-lipoic acid: a 7-month multicenter randomized controlled trial (ALADIN III Study). ALADIN III Study Group. Alpha-Lipoic Acid in Diabetic Neuropathy. Diabetes Care 22: 1296-1301 
75. Jamal GA (1994) The use of gamma linolenic acid in the prevention and treatment of diabetic neuropathy. Diabet Med 11: 145-149

76. Keen H, Payan J, Allawi J et al. (1993) Treatment of Diabetic Neuropathy with $\gamma$-Linolenic Acid. Diabetes Care 16: 8-15

77. Miyauchi Y, Shikama H, Takasu T et al. (1996) Slowing of peripheral motor nerve conduction was ameliorated by aminoguanidine in streptozocin-induced diabetic rats. Eur J Endocrinol 134: 467-473

78. Schmidt RE, Dorsey DA, Beaudet LN, Reiser KM, Williamson JR, Tilton RG (1996) Effect of aminoguanidine on the frequency of neuroaxonal dystrophy in the superior mesenteric sympathetic autonomic ganglia of rats with streptozotocin-induced diabetes. Diabetes 45: 284-290

79. Nargi SE, Colen LB, Liuzzi F, Al-Abed Y, Vinik AI (1999) PTB treatment restores joint mobility in a new model of diabetic cheirothropathy. Diabetes 48 [Suppl 1]: A17 (Abstract)

80. Suez D (1995) Intravenous immunoglobulin therapy: indication, potential side effects and treatment guidelines. J Intraven Nurs 18: 178-190

81. Diemel LT, Stevens JC, Willars GB, Tomlinson DR (1992) Depletion of substance P and calcitonin gene-related peptide in sciatic nerve of rats with experimental diabetes: effects of insulin and aldose reductase inhibition. Neurosci Lett 137: 253-256

82. Hellweg R, Wohrle M, Hartung HD (1991) Diabetes mellitus associated decrease in nerve growth factor levels is reversed by allogenetic pancreatic islet transplantation. Neurosci Lett 125: 1-4

83. Tomlinson DR, Fernyhough P, Diemel LT (1996) Neurotrophins and peripheral neuropathy. Philos Trans R Soc Lond B Biol Sci 351: 455-462

84. Apfel SC, Kessler JA (1995) Neurotropic factors in the therapy of peripheral neuropathy. Baillieres Clin Neurol 4: 593-606

85. Sindrup SH, Jensen TS (1999) Efficacy of pharmacological treatments of neuropathic pain: an update and effect related to mechanism of drug action. Pain 83: 389-400

86. Rains C, Bryson HM (1995) Topical capsaicin. A review of its pharmacological properties and therapeutic potential in post-herpetic neuralgia, diabetic neuropathy and osteoarthritis. Drugs Aging 7: 317-328

87. Bays-Smith MG, Max MB, Muir J, Kingman A (1995) Transdermal clonidine compared to placebo in painful diabetic neuropathy using a two-stage 'enriched enrollment' design. Pain 60: 267-274

88. Jarvis B, Coukell AJ (1998) Mexiletine. A review of its therapeutic use in painful diabetic neuropathy. Drugs 56: 691-707

89. Harati Y, Gooch C, Swenson M et al. (1998) Double-blind randomized trial of tramadol for the treatment of the pain of diabetic neuropathy. Neurology 50: 1842-1846

90. Nelson KA, Park KM, Robinovitz E, Tsigos C, Max MB (1997) High-dose oral dextromethorphan versus placebo in painful diabetic neuropathy and postherpetic neuralgia. Neurology 48: 1212-1218

91. Max M, Lynch S, Muir J (1992) Effects of desipramine, amitryptylline and fluoxetine on pain in diabetic neuropathy. N Engl J Med 326: 1250-1256

92. McQuay H, Carroll D, Jadad AR, Wiffen P, Moore A (1995) Anticonvulsant drugs for management of pain: a systematic review. BMJ 311: 1047-1052

93. Gorson KC, Schott C, Herman R, Ropper AH, Rand WM (1999) Gabapentin in the treatment of painful diabetic neuropathy: a placebo controlled, double blind, crossover trial. J Neurol Neurosurg Psychiatry 66: 251-252

94. Backonja M, Beydoun A, Edwards KR et al. (1998) Gabapentin for the symptomatic treatment of painful neuropathy in patients with diabetes mellitus. JAMA 280: 1831-1836

95. Vinik A, Fonseca V, LaMoreaux L, Hes M, Koto E (1998) Neurontin (Gabapentin, GBP) improves quality of life (QOL) in patients with painful diabetic peripheral neuropathy. Diabetes [Suppl 1] 47: A374 (Abstract)

96. Somers DL, Somers MF (1999) Treatment of neuropathic pain in a patient with diabetic neuropathy using transcutaneous electrical nerve stimulation applied to the skin of the lumbar region. Phys Ther 79: 767-775

97. Zieleniewski W (1990) Calcitonin nasal spray for painful diabetic neuropathy. Lancet 336: 449

98. Cavanagh PR, Derr JA, Ulbrecht JS, Maser RE, Orchard TJ (1992) Problems with gait and posture in neuropathic patients with insulin-dependent diabetes mellitus. Diabet Med 9: 469-474

99. Nelson ME, Fiatarone MA, Morganti CM, Trice I, Greenberg RA, Evans WJ (1994) Effects of high-intensity strength training on multiple risk factors for osteoporotic fractures. A randomized controlled trial. JAMA 272: 1909-1914

100. Athyros VG, Didangelos TP, Karamitsos DT, Papageorgiou AA, Boudoulas H, Kontopoulos AG (1998) Longterm effect of converting enzyme inhibition on circadian sympathetic and parasympathetic modulation in patients with diabetic autonomic neuropathy. Acta Cardiol 53: 201-209

101. Malmberg K, Norhammar A, Wedel H, Ryden L (1999) Glycometabolic state at admission: important risk marker of mortality in conventionally treated patients with diabetes mellitus and acute myocardial infarction: long-term results from the Diabetes and Insulin-Glucose Infusion in Acute Myocardial Infarction (DIGAMI) study. Circulation 99: 2626-2632

102. Kendall DM, Rooney DP, Smets YF, Salazar Bolding L, Robertson RP (1997) Pancreas transplantation restores epinephrine response and symptom recognition during hypoglycemia in patients with long-standing type I diabetes and autonomic neuropathy. Diabetes 46: 249-257

103. Burger AJ, Weinrauch LA, D'Elia JA, Aronson D (1999) Effects of glycemic control on heart rate variability in type I diabetic patients with cardiac autonomic neuropathy. Am J Cardiol 84: 687-691

104. Laederach-Hofmann K, Weidmann P, Ferrari P (1999) Hypovolemia contributes to the pathogenesis of orthostatic hypotension in patients with diabetes mellitus. Am J Med 106: 50-58

105. Denq JC, Opfer-Gehrking TL, Giuliani M, Felten J, Convertino VA, Low PA (1997) Efficacy of compression of different capacitance beds in the amelioration of orthostatic hypotension. Clin Auton Res 7: 321-326

106. Annese V, Bassotti G, Caruso N et al. (1999) Gastrointestinal motor dysfunction, symptoms, and neuropathy in noninsulin-dependent (type 2) diabetes mellitus. J Clin Gastroenterol 29: 171-177

107. Melga P, Mansi C, Ciuchi E, Giusti R, Sciaba L, Prando R (1997) Chronic administration of levosulpiride and glycemic control in IDDM patients with gastroparesis. Diabetes Care 20: 55-58

108. Stacher G, Schernthaner G, Francesconi M et al. (1999) Cisapride versus Placebo for 8 weeks on glycemic control and gastric emptying in insulin-dependent diabetes: a 
double blind cross-over trial. J Clin Endocrinol Metab 84: 2357-2362

109. Barone JA (1999) Domperidone: a peripherally acting dopamine2-receptor antagonist. Ann Pharmacother 33: 429-440

110. Silvers D, Kipnes M, Broadstone Vet al. (1998) Domperidone in the management of symptoms of diabetic gastroparesis: efficacy, tolerability, and quality-of-life outcomes in a multicenter controlled trial. DOM-USA-5 Study Group. Clin Ther 20: 438-453

111. Erbas T, Varoglu E, Erbas B, Tastekin G, Akalin S (1993) Comparison of metoclopramide and erythromycin in the treatment of diabetic gastroparesis. Diabetes Care 16: $1511-1514$
112. Vinik AI, Richardson D (1998) Erectile dysfunction in diabetes. Diabetes Reviews 6: 1633-1633

113. Vinik AI, Richardson D (1998) Erectile dysfunction in diabetes: pills for penile failure. Clinica Diabetes 16: 108-119

114. Price DE (1998) Erectile dysfunction in patients with diabetes: meta-analysis of 9 sildenafil $\left(\right.$ Viagra $\left.^{\circledR}\right)$ studies. Diabetologia 41 [Suppl 1]: A51 (Abstract)

115. Shaw JE, Parker R, Hollis S, Gokal R, Boulton AJ (1996) Gustatory sweating in diabetes mellitus. Diabet Med 13: 1033-1037

116. Shaw JE, Abbott CA, Tindle K, Hollis S, Boulton AJ (1997) A randomised controlled trial of topical glycopyrrolate, the first specific treatment for diabetic gustatory sweating. Diabetologia 40: 299-301 